\title{
Aerothermal Analysis of the Project Fire II Afterbody Flow
}

\author{
Michael Wright, ${ }^{*}$ Mark Loomis, ${ }^{\dagger}$ and Periklis Papadopoulos $\$$ \\ NASA Ames Research Center \\ Moffett Field CA, 94035
}

\begin{abstract}
Computational fluid dynamics is used to simulate the wake flow and afterbody heating of the Project Fire II ballistic reentry to Earth at $11.4 \mathrm{~km} / \mathrm{sec}$. Laminar results are obtained over a portion of the trajectory between the initial heat pulse and peak afterbody heating. Although forebody convective heating results are in excellent agreement with previous computations, initial non-catalytic predictions of afterbody heating were about a factor of two below the experimental values. However, analogy with currently produced thermal protection materials suggests that significant catalysis may be occurring on the afterbody heat shield. Computations including finite-rate catalysis on the afterbody surface are in good agreement with the data over the early portion of the trajectory, but are conservative near the peak afterbody heating point, especially on the rear portion of the conical frustum. Further analysis of the flight data from Fire II shows that peak afterbody heating on the frustum occurs before peak forebody heating, a result that contradicts computations and flight data from other entry vehicles. This result suggests that another mechanism, possibly pyrolysis, may be occurring during the later portion of the trajectory, resulting in less total heat transfer than the current predictions.
\end{abstract}

\section{Introduction}

Thirty six years later, the Project Fire II ballistic: rentry to Earth at it nominal velocity of $11.1 \mathrm{~km} / \mathrm{s}$ rematius one of the best sources of aerothermal heating diat a for the design of sample return capsules. The data from this flight experiment ${ }^{1-3}$ encompass both the thermodemical nom equilibrium and equilibrium flow regimes and include measurements of both radiative and total heating on the forebody and afterbody. Because of the quality of this data, a number of researchers have performed computational fluid dynamics (CID) simulation of the forebody of the Fire II entry vehicle, ${ }^{4-4}$ with generally good results. In particular, Olynick et.al. ${ }^{4}$ roupled a Navier-Stokes solver wit h a nonequilibrium radiation code and showed good agrement for stagnation point heat transfer over the Fire 11 rajectory between 1631 and 1651 seconds (77 km to $: 3 \mathrm{~km}$ ), a period that encompassed the peak forcbody heating point $(t=1645 s)$. However, in most rasen the primary motivation of the previous work was to model the coupling between shock layer radiation and aerothermorlynamics, and thus the sim-

\footnotetext{
* Rrucarch Scicntist, ELoRET Gorp., Mrmber AlAa

+ Rescarch Scicntist, Reacting Flow Environments Branch, Scnior Mambor AlAA

I Sinior Roserum Sciontist, ELORET Corp.

Copyright (O) 2001 by the American Institute of Acronatics and Astronanties, Ine. No anplifht is asserted in the United States under Title 17, US. Cads. The li.S. government has a royaltyfree license to excreise all riphts under the ewpright clamed lecrein for gowernment purposes. All other rights are reserved by the copyright haider.
}

ulations concentrated on the forebody flow only. To our knowledge there have been no prior published at tempts to reproduce the afterbody heating data presented in Ref. 3.

Uncertainties in afterbody heating predictions can have a major impact on Thermal Protection System (TPS) material selection and weight. Conservatism in the afterbody heat shield design will shift tho center of gravity backwards, reducing stability and in some cases necessitating ballast in the nose. Current design practices for afterbody heatshields typically assurre a laminar, fully-catalytic, non ablating surface. The predictions thus obtained are angmented by a large factor of safety to account for turbulent tramsition and uncertainty in the baseline computations. The main reason for this uncertainty is a sparsity of dala for val idation of our computational tools. Crround test data are typically complicated by sting interference effects. although a limited amount of shock tumel data are available." Little flight data at the appropriate entry velocities exist, and recent attempts to propose dedi cated flight experiments have failed to reach fruition. Therefore, it is important to understand the lintited flight data that are available to improve the design fidelity of the next generation of Farth and planetary entry vehicles and to assess the need for atditional flight datit. In this paper we take a first step towards in undertanding of the afterbody heating data from the Project Fire Il fight experiment. 


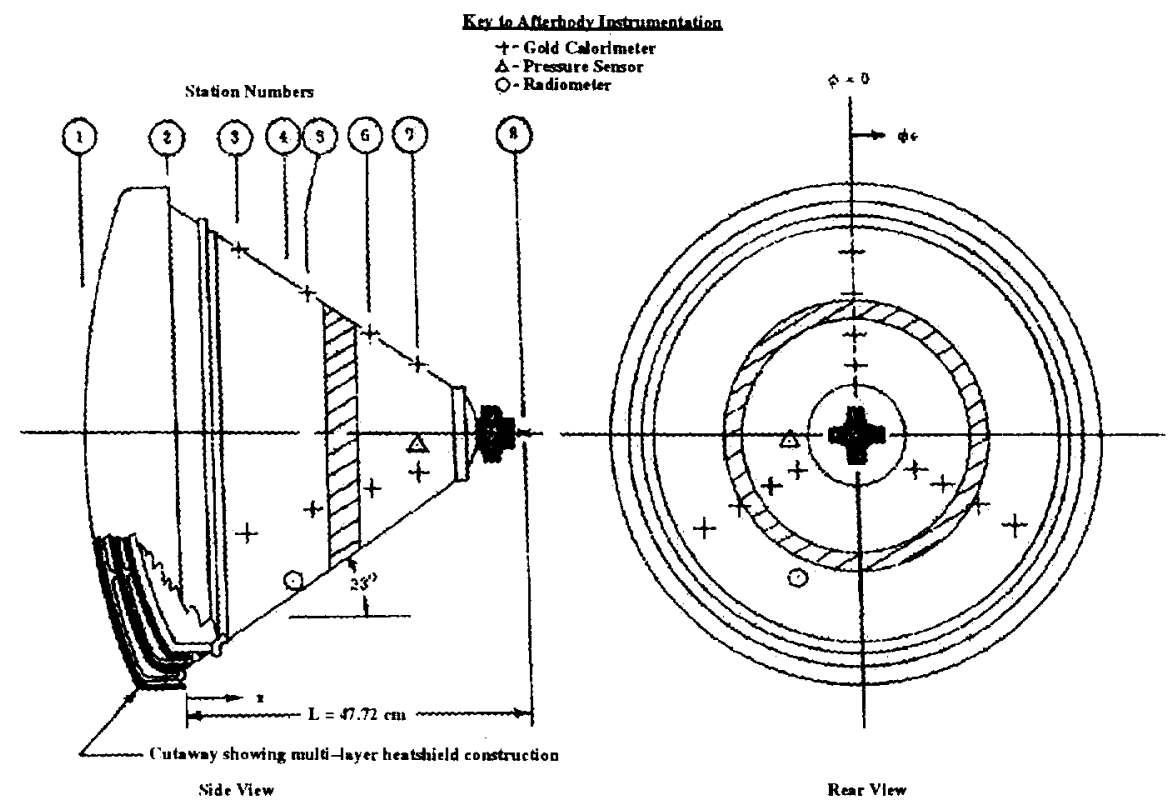

Figure 1. Schematic of the Fire II reentry vehicle showing multiple forebody heatshields and afterbody instrument placement. Station numbers correspond to those in Table 1. (Adapted from Ref. 3)

\section{Geometry and Instrumentation}

Tho Fire II reentry vohicle consisted of a multilayer configuration mitule up of three phenolic asbestos heat shields sandwichnd between beryllium calorimeters. Figure 1, taken from Ref. 3 , is a schematic of the vehicle showing the configuration of each calorimeter. The first two alorimotors and their associated heat shields were designed to be ejected after the onset of melting, yielding three separate data-gathering periods. Forebody instrumentation consisted of thermo. couples and forward looking radiometers. (See Refs. 12 for details on forebody instrumentation and placement.)

The $66^{\circ}$ included angle conical afterbody section was constructed of a fibergl tis shell supporting a layer of phenolic-asbestos heat protection materiat. A thin surface coating of silicon elastomer was added for prelannch moisture protection. The conical frustum portion of the afterbody was instrumented with a symmetrical array of 12 gold calorimeters, distributed at three circumferential locations and four $x$-stations on the frustum, as shown in Fig. 1. In addition, a single rearward-facing radioneter was placed on the frustum, ako shown in Fig. 1. Details of the afterbody instru ment placement are given in Table 1. The published uncertainty of the thermocouples at the base of each ralorimeter was $\pm 28 \mathrm{~K}$ over the measured temperature range 3 Raw temperature data were converted to mimates of total surface heat transfer by a curve fit- ting procedure. ${ }^{10}$ Uncertainty in the final heat transfer obtained is not given, however we assume here that the uncertainty in the computation of the temperature gradient is of the same order as the uncertainty in $T$. This, coupled with published uncertainties in other steps of the data reduction process, ${ }^{16}$ yield an estimated total uncertainty in heat transfer of $\pm 15 \%$. The rearward facing radiometer indicated zero radiation during the entire entry with the exception of one brief pulse correlated to a forebody heatshield ejection event. Since the intensity threshold of the radiometer was approximately $1 \mathrm{~W} / \mathrm{cm}^{2}$ in the 0.2 to 1.0 micron range, and since the single flash indicated that the radiometer was indeed functioning, it is concluded that the afterbody heating rates consisted mainly of convective heating. ${ }^{3}$ Further details on the instrumentation and data reduction procedures are available in Refs. 3 and 10

Althongh the published reports give sufficient infor mation to accurately determine the forebody geometry, complete information for the entire vehicle is more difficult to obtain. By compiling geometrical data from several sources ${ }^{1,3,11}$ we were able to construct an accurate (although somewhat simplified) outer mold line (OML) for the first heat shield configuration, shown in Fig. 2. The primary simplification that was made during construction of the OML was the elimination of the C-band antenna, which can be seen at the base of the vehicle in Fig. 1. This modification wa made to 


\begin{tabular}{|c|c|c|}
\hline Station & Sensor Type & $x / L$ \\
\hline 2 & Beginning of Frustum & 0 \\
\hline 3 & $\begin{array}{l}3 \text { Calorimeters } \\
\phi=0^{\circ}, 120^{\circ}, 210^{\circ}\end{array}$ & 0.19 \\
\hline 1 & $\begin{array}{c}1 \text { Radiometer } \\
\phi=203.15^{\circ}\end{array}$ & 0.32 \\
\hline 5 & $\begin{array}{c}3 \text { Calorimeters } \\
\phi=0^{\circ}, 120^{\circ}, 210^{\circ}\end{array}$ & 0.38 \\
\hline 6 & $\begin{array}{c}3 \text { Callorimeters } \\
\phi=0^{\circ}, 120^{\circ}, 210^{\circ}\end{array}$ & 0.56 \\
\hline 7 & $\begin{array}{c}\Leftrightarrow \text { Calorimeters } \\
\phi=0^{\circ}, 120^{\circ}, 210^{\circ} \\
1 \text { Pressire Sensor, } \phi=265^{\circ}\end{array}$ & 0.70 \\
\hline 8 & Theoretical cone apex & 1.0 \\
\hline
\end{tabular}

Tablo 1 Instrument placement on Fire II afterbody. Station numbers and $x / L$ locations refer to Fig. $1 . \phi$ refers to the circumferential location of the sensor.

allow for axisymmetric solutions to be obtained (the antelua is three-dimensional), and also because exact dimensions for the antemna could not be located. Since all instrumentation was placed on the conical frustum well away from the (: band antenna, this approximation should not greatly affect the computed results. In addition, a small backward facing step resulting from the at tachment of the third forebody heatshield to the vehicle was eliminated, again due to a lack of geometric information. We are still working to completely define these details of the OML.

As stated above, the forebody consisted of three alorimeter/heat shield combinations that were designed to be ejected after the onset of melting. 'This configuration effectively divided the data-gathering window into three discrete periods, interspersed with brief periods where the heatshield ejection process and reultant flowfield interaction made accurate data gathering impossible. The data periods bracket the peak forebody heating portion of the entry trajectory. Althongh the nominal angle of attack of the vehicle was $0^{\circ}$, the heatshield cjection process introduced significall off-axis forces to the reentry vehicle, resulting in successively larger angles of attack with time. Based on flight telemetry data, the angle of attack was less than $1^{\circ}$ for the first dat a period, $5^{\circ}$ during the second, and an much as $11^{\circ}$ during the third period. ${ }^{3}$ For this and other reasons (discussed below), the analysis presented here is limited to the first data period, which span the onset of significant afterbody heating to the pesk hesting period on the conical frustum.

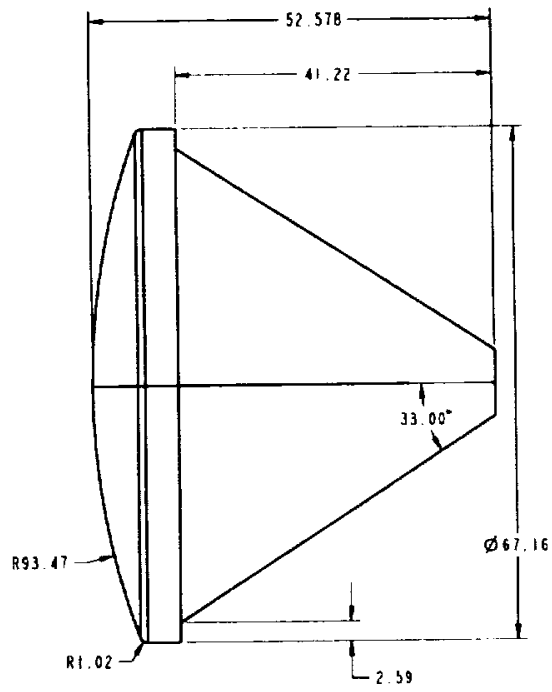

Figure 2. Relevant dimensions of the Fire II reentry vehicle outer mold line (OML) as modeled in the CFD simulations. All dimensions are in centimeters.

\section{Physical and Numerical Modeling}

A detailed description of the relevant equations for reentry flows has been presented in a number of sources ${ }^{12-14}$ and will not be repeated here. Velocities during the portion of the Fire II trajectory considered here were in excess of $11 \mathrm{~km} / \mathrm{sec}$ at an altitude range between 75 and $60 \mathrm{~km}$. At these conditions the postshock flowfield is in a state of thermal and chemical nonequilibrium, and a significant atmount of ionization is expected. 'Therefore, the flow is modeled nsing an 11-species $\left(\mathrm{N}_{2}, \mathrm{O}_{2}, \mathrm{NO}, \mathrm{N}, \mathrm{O}, \mathrm{N}_{2+}, \mathrm{O}_{2+}, \mathrm{NO} \mathrm{O}_{+}, \mathrm{N}_{+}\right.$, $O_{+}$, e) 17 reaction finite-rate air chemistry model. The chemical source terms are modeled using rates from Park, ${ }^{15}$ with the exception of the rates for the electron impact ionization reactions, which are taken from Wilson. ${ }^{16}$ The governing temperature for the electron impact ionization reactions is assumed to be the heavy particle translational temperature $(T)$ based on earlier work by Olynick. ${ }^{4}$ The flow is modeled assuming thermal non-equilibrium, with separate equations for conservation of vibrational and total energies. 'The coupling between the translational and vibrational energy modes is modeled using a Landau-Teller formulation, where relaxation times are obtained from Millikan and White, ${ }^{17}$ assuming simple harmonic oscillators.

Viscous transport and thermal conductivity are modeled using the collision cross-section fits of (iupta. ${ }^{1 \text { * }}$ The bifurcation method ${ }^{15}$ is used to model binary diffusion, with the reference binary diffusion coefficient $\left(\mathcal{D}_{N_{2}-N_{2}}\right)$ computed using the Gupta fits. This method allows for variations in species diffusion coefficients to be modeled without ancrificing the requirement that 
the diffusion velocities sum identically to zero. The diffusion velocity of the electrons is computed from the requirement of zero current density in the flow. The entire flowfield is issumed to be laminar, which should be a good assumption, given the low freestream Reynolds numbers (see Table 2) during the early portion of the entry. The assumption of laminar flow in the near wake was validated using blunt body separation shear layer and inner wake transition correlations given by Lees. ${ }^{20}$ Even for the final (highest Re) trajectory point simulated the local Reynolds number in the shear layer $\left(R f_{l}\right)$ was more than an order of magnitude below the transition Reynolds number, and the wake transition correlation indicated laminar flow for more than eleven body diameters downstream. Since the sonic point in the neck region was only about $2.5 \mathrm{di}-$ ameters downstream, we conclude that transition will not affect the separated flow region.

Surface catalysis is modeled using a diffusion lim ited approach, ${ }^{21}$ in which the rate of production of a species at the wall is halanced by the rate of mass diffusion of the constituent species, ie.

$$
\left.\rho_{s} \prime_{*}\right|_{u}=\left.\dot{w} \cdot\right|_{w},
$$

where $\rho_{s}$ is the species density, $\left.\nu_{a}\right|_{w}$ is body-normal diffusion velocity of species $s$ at the wall and $\left.w_{s}\right|_{w}$ is the rate of production, modeled with a first order reaction rate as

$$
\left.\dot{w}\right|_{w}=\rho_{s} \gamma_{s} \sqrt{\frac{\mathcal{R} T_{w}}{2 \pi M_{s}}}
$$

where $\mathcal{R}$ is the universial gas constant, $T_{t u}$ is the wall temperature, $M$, is the species molecular weight, and $\gamma_{s}$ is an accommodation coefficient representing the fraction of at oms or ions that recombine upon reaching the wall.

We assume that the surface of the beryllium forebody is completely oxidized by the high concentration of $O$ atoms in the shock layer, and is thus non-catalytic to neutrit epecies (Tneusrals $=0$ ). However, the surface is assumed to be uncharged, and thus fully catalytic to ion recombination $\left(\gamma_{i o n}=1\right) .{ }^{21}$ This assumption was shown previously to yield stagnation point heat transfer predictions in good agreement with the flight data. In atdition, while the catalycity of oxidized beryllium in a reentry environment is not known, there is a large amount of experimental data indicating that oxidized metals are much less catalytic that their "clean" counterparts, $22-23$ and that an oxide with low electrical conductance, such as beryllium oxide, should be a poor catalyst. The afterbody sur

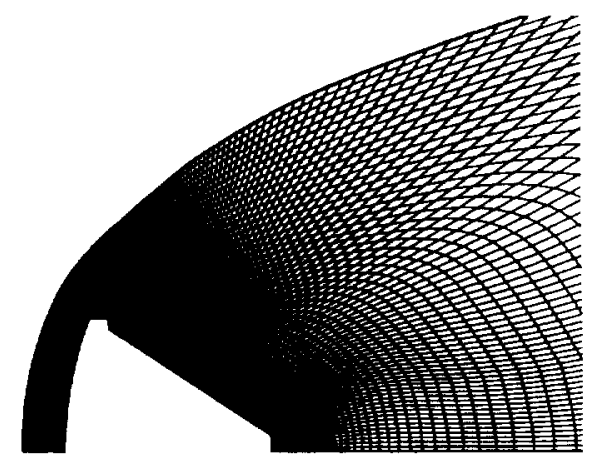

a)

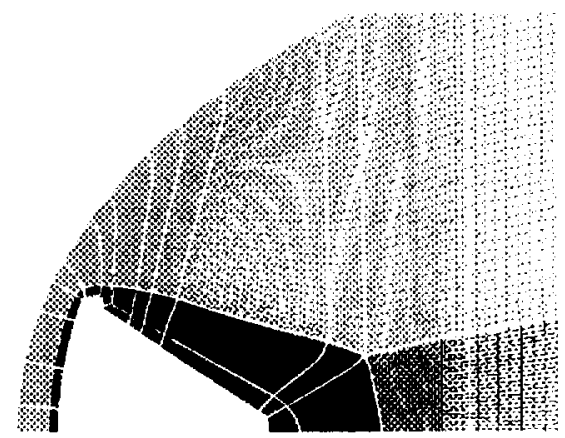

Figure 3. Grid topologies used in this work, enlarged to show detail near the body surface. a) Single block hyperbolic grid and b) Five block grid with compact enrichment in wake region. White lines delineate elemental blocks.

face coating is silicon elastomer, which wats also initially assumed to be non-catalytic to neutral species and fully catalytic to ions. This assumption will be examined further in the results section. An isothermal wall boundary condition was applied on the highly conductive metallic forebody, with the wall temperature at each time period taken from the thermocouple data. Both a cold wall and a radiative equilibrium wall boundary condition were considered for the after body, with details given in the results. A no-slip wall velocity boundary condition was applied on the entire surface. Freestream conditions were based on atmo. spheric soundings taken immediately after the flight. "1

The CFD code used to obtain solutions for this paper was DPLR-Axi. ${ }^{24}$ DPLR-Axi is a parallel multiblock axisymmetric extended Navier-Stokes solver, based on algorithms developed in GIANTS, ${ }^{4}$ that incorporates all of the physical models discussed above. The Euler fluxes are computed using a modified form of Steger-Warming flux vector splitting, ${ }^{25}$ which significantly reduces the dissipation of the original scheme. 


\begin{tabular}{cccccc}
\hline $\begin{array}{c}\text { Time } \\
(\mathrm{sec})\end{array}$ & $\begin{array}{c}\text { Altitude } \\
(\mathrm{km})\end{array}$ & Rfo & $\begin{array}{c}\text { Velocity } \\
(\mathrm{km} / \mathrm{s})\end{array}$ & $\begin{array}{c}\text { Density } \\
\left(\mathrm{kg} / \mathrm{m}^{3}\right)\end{array}$ & $\begin{array}{c}T_{\infty} \\
(\mathrm{K})\end{array}$ \\
\hline 1631 & 76.12 & $2 \times 10^{4}$ & 11.36 & $3.72 c-5$ & 195 \\
1636 & 71.04 & $5 \times 10^{-4}$ & 11.31 & $8.57 c-5$ & 210 \\
1637.5 & 67.05 & $7 \times 10^{4}$ & 11.25 & $1.17 \epsilon-1$ & 228 \\
1639 & 63.11 & $1 \times 10^{5}$ & 11.11 & $2.11 c-1$ & 242 \\
1610.5 & 59.26 & $2 \times 10^{5}$ & 10.97 & $3.86 c-1$ & 251 \\
\hline
\end{tabular}

Table 2 Fire II trajectory points and freestream conditions. ReD is the freest ream Reynolds number based on body diameter. Time is given in seconds after launch.

Third-order spatial accuracy is obtained through MUSCL extrapolation, coupled with a minmod limiter. ${ }^{26}$ Time indyancement to as steady state solution is achieved using the data-parallel line relaxation method. ${ }^{24}$ This code has been previously applied successfully to several problems. ${ }^{27-28}$ DPLR $A x i$ typically required about 10.000 iterations to reach a steady-state solution on the bateline $(161 \times 97)$ single block grid (as compared to abont 1000 iterations for a forebody only case), and required approximately $3:$ CPU hours on a SGI R12000 worlintation. The litge scale flow features were set up fairly quickly, but the afterbody heat transfer, especially on the flat base plate, converged to its final answer very slowly.

Wake flows an besensitive to details of the volume grid comstruction, and care must be taken to generate a grid that is woll aligned to the flow features. In particular, it is important to accurately capture the rapid expansion around the shoulder, which determines the thermochemical state of the essentially frozen wake. The nature of the separated flow region is also determined in large part by the shear layer and wake compression region. ${ }^{26}$ At higher Reynolds numbers the wake will consist of multiple counter-rotating vortices, which must be resolved." Finally, care must be taken to amsure that the grid completely encloses the subsonic portion of the wake, which can extend several body dianeters downtream. For this paper, solutions were obtained using two grid topologies. The first topology, shown in Fig. ia, consists of a single mesh block constructed using a hyperbolic grid generator ${ }^{31}$ to ensure orthogonality at the surface. The solution adiptive grid code $\mathrm{SAC}^{2 \mathrm{BE}^{32}}$ is used to fit the bound ary to the computed shock. This topology allows for rapid grid generation and solution turnaround, and should be aderpuate for preliminary heat shield design, as well at for the computation of low Reynolds number llows where the withe strueture is dominated by a single large vortex. However, as the Reynolds number increatse and the wate becomes more complex, it is desirable to use a grid topology that allows for compact enrichment of the separated flow region without propagation of the grid points throughout the rest of the grid. The second grid (Fig. 3b), constructed using GridPro, ${ }^{33}$ allows for compact enrichment with a topology that results in 36 elemental blocks, merge able into four. With such a topology the grid in the separation region can be arbitrarily densified without increasing the point density in the rest of the grid. With either topology, SAGE ${ }^{32}$ is used to adapt the grid to the computed solution and cluster points near flow features of interest.

\section{Results}

Solutions were obtained for five trajectory points during the first data period, with freestream condi tions listed in Table 2. The solutions range from 1631 to 1610.5 seconds after launch, which spans the period from the first appreciable afterbody heat transfer measurements to a point near peak afterbody heating. Solutions were limited to the first data period for several reasons, including the desire for laminar axisymmet ric steady flow and the lack of complete geometric information for the second and third forebody calorimeter configurations. It should be noted that the final trajectory point, at $t=1610.5 \mathrm{~s}$, occurs after the onset of forebody calorimeter melting. Therefore, it is possible that the accuracy of the afterbody data may be compromised by beryllium droplets entrained in the wake. However, the temperature vs. time traces for the afterbody thermocouples show no anomalous readings that can be traced to forebody melting.

\section{Wake Structure}

Figure 1 shows streamlines in the separated flow region for all five trajectory points. All solutions were obtained on the baseline single block grid, which has 161 points along the body surface and 97 points in the normal direction. At the lowest Reynolds number point $(t=1634 \mathrm{~s})$ the flow separates on the coni cal frustum well after the heatshield shoulder, and is dominated by a single large vortex. As the Reynolds number (and $t$ ) increases, the separated flow region becomes larger and more complex, as would be $\mathrm{ex}$ pected for a laminar flow. At $t=1636 \mathrm{~s}$ and $t=1637.5 \mathrm{~s}$ the flow separates at the rearward facing step after the shoulder, but remains dominated by a single vor tex. However, by $t=1639 \mathrm{~s}$ a bulge can be seen about a third of the way down the conical frustum, which can be further resolved into a small secondary vortex. Additional small vortices appear in the corners of the rearward facing steps at the rear shoulder and base 


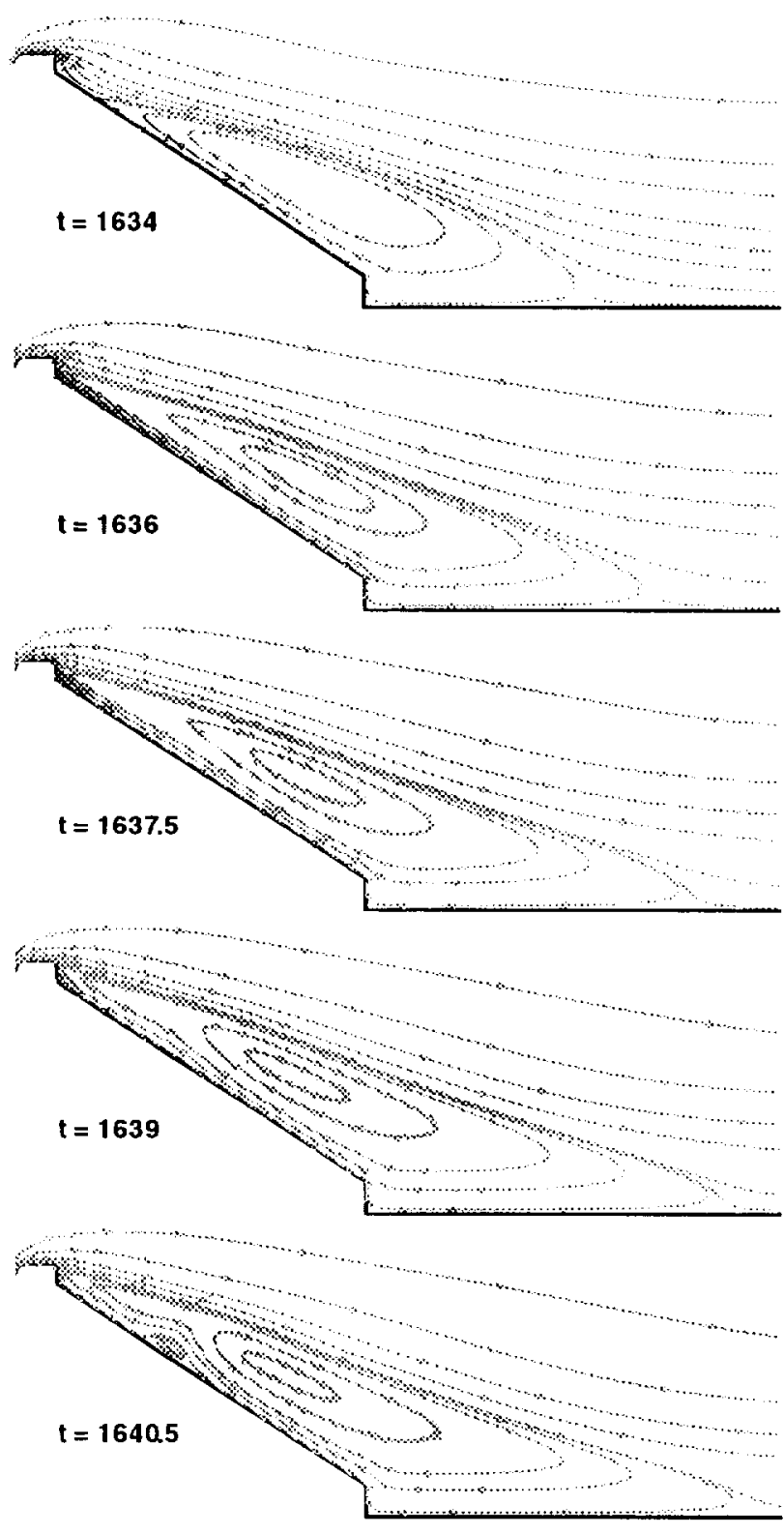

Figure 4. Streamlines in the separated flow region for solutions between $t=1684 \mathrm{~s}$ and $t=1640.5 \mathrm{~s}$, showing evolution of the wake structure.

of the probe. Finally, by $t=1610.5 \mathrm{~s}$ a well developed secondary vortex is apparent on the frustum. While all computations predict these flows to be steady, it is likely that as the Reynolds number increases further the secondary vortices will begin to move and the flow will become unsteady. ${ }^{34}$

\section{Surface Heating}

Figure 5 a shows the computed total convective $\left(i_{t}\right)$ and the catalytic component $\left(\dot{q}_{c a t}\right)$ of heat trans

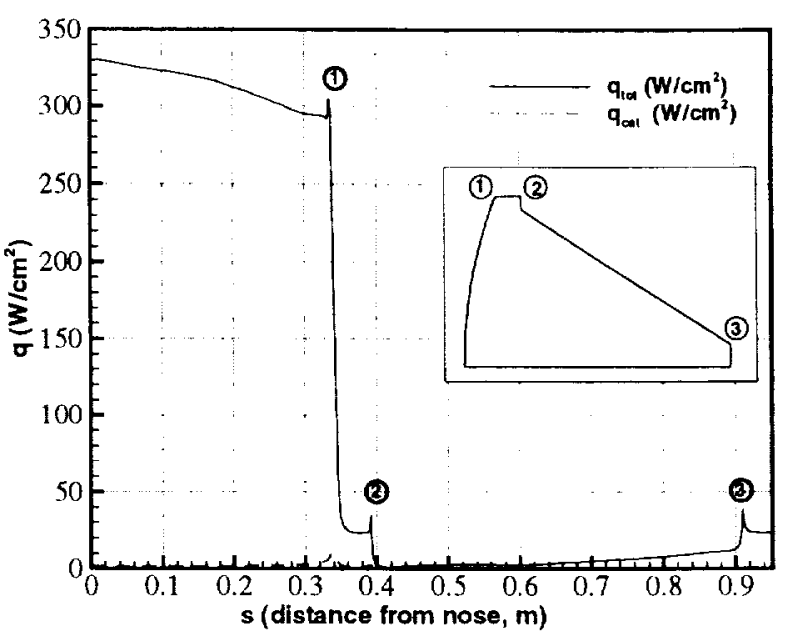

a)

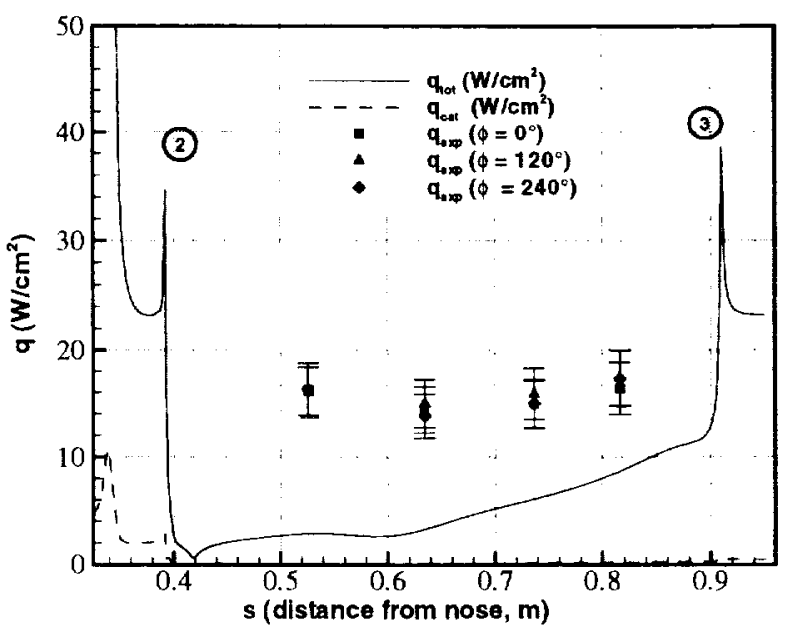

b)

Figure 5. Computed total convective $\left(\dot{q}_{t, t}\right)$ and catalytic component $\left(\dot{q}_{c a t}\right)$ of heat transfer to the body surface at $t=1639 \mathrm{~s}$. a) Entire vehicle, and b) enlargement of the afterbody region with experimental data from the twelve calorimeters.

fer to the surface at $t=1639 \mathrm{~s}$. Data are plotted vs. $s$, the pathlength distance from the apex of the vehicle. The surface was assumed to be non-catalytic to neutral species and fully catalytic to ions. The isothermal wall temperature $\left(T_{w}=1325 \mathrm{~K}\right)$ was taken from the fore body thermocouple data. The solution was obtained on the baseline $161 \times 97$ grid, with the wall spacing chosen to maintain a constant cell Reynolds number $\left(R e_{c}=2\right)$ on the surface. The effects of grid resolution and varying wall spacing will be examined below. It is impossible to directly compare our forebody convec. tive heating results to the experimental data, which are based on total (convective and radiative) heating. However, from Fig. 5 a we see that the stagnation con 
vective heating is about $330 \mathrm{~W} / \mathrm{cm}^{2}$, which is within $5 \%$ of the value reported by Olynick et al. ${ }^{4}$ using a similar set of modeling assumptions. The catalytic component of heating is negligible on the entire surface, comprising about $2 \%$ of the total heat transfer. This is because most of the ions recombine in the cold boundary layer before reaching the surface.

The flow undergoes a patir of rapid expansions at the heatshield shoulder (point 1 in Fig. 5a) and the rearward facing step (point 2), which result in a local increase in heat transfer during the expansion, followed by a rapid decrease. An enlargement of the afterbody region is shown in Fig. 5b. 'The numbers in Fig. 5b correspond to the inset in Fig. 5a. Also included in this figure are the experimental data from each of the 12 calorimeters. Since the calorimeters were placed in a symmetrical array, there are three points at each $s-$ location, corresponding to different circumferential $(\phi)$ locations. The experimental data show that there is little circumferential dita scatter, which is consistent with the small angle of attack $\left(\alpha<1^{\circ}\right)$ reported during the first data period. However, the computation predicts at heat transfer rate that is considerably lower than the experimental data. Although not shown here, the same trend is observed for the other trajectory points. The rather poor comparison between the ini tial computations and the data is not too surprising, considering the simplistic nature of the boundary con dition that were initially imposed at the surface. In the next sections of the paper we look at several model ing assumptions that were made in order to determine their affect on computed heat transfer.

\section{Grid sensitivity}

One possibility for the poor agreement between the computation and experiment is grid resolution. In order to examine this effect, grid refinement studies were conducted at the $t=16.34$ and $t=16.39$ second trajectory points, covering at range of Reynolds numbers be1 ween $2 \times 10^{4}$ to $1 \times 10^{5}$ bised on body diameter. The number of grid points in the axial and normal direction as well as the body normal spacing were varied to determine their effect on computed heat transfer.

Figure 6 shows representative results at $t=1639 \mathrm{~s}$. Solntions are shown on three grids. Only the afterbody region is shown in Fig. 6 ; the forebody heat trans fer varied by less than $1 \%$ on all grids tested (slightly larger deviations were seen at the stagnation point due 10 mmorical issues witl some of the grids). The baseline grid (" $A$ ") bas 1 lil points along the body surface and 97 points in the nommal direction. Wall spacing was chosen to maintain a constant cell Reynolds num

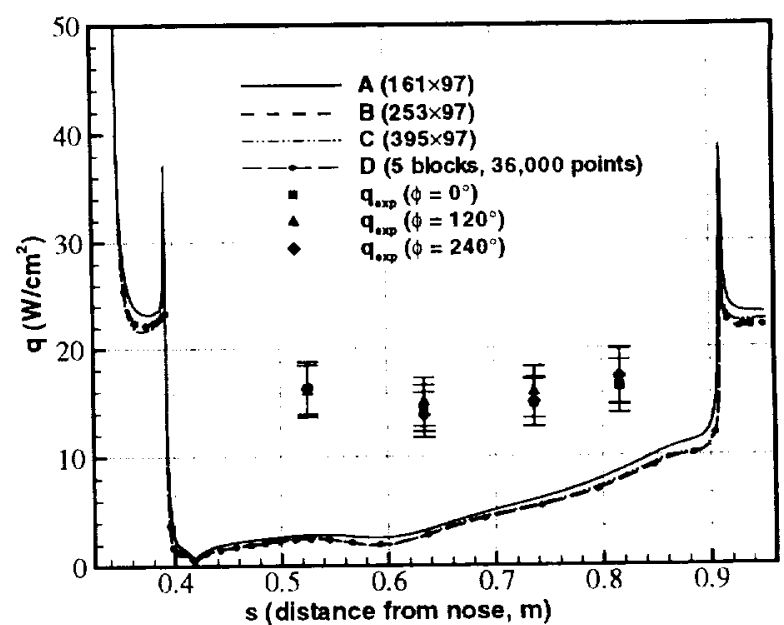

Figure 6. Impact of grid resolution on the computed heat transfer at $t=1639 \mathrm{~s}$. 'The first grid is the baseline grid used in this paper. The next two solutions were obtained on single block grids with increasing axial resolution. The final case was obtained on a four block grid with compact enrichment of the wake core.

ber $\left(R e_{c}=2\right)$, which implies that the near wall spacing in the low density afterbody is much larger than on the forebody. The second grid ("B") was refined in the axial direction only, with 253 axial points clustered near the shoulder and geometric comers on the afterbody. The normal spacing was identical to the previous grid. From Fig. 6 we see that the increased axial resolution lowered the predicted heat transfer by $10-15 \%$. This trend is consistent with the results of Olynick, ${ }^{34}$ who showed that the corner expansion plays a significant role in determining heat transfer on the afterbody for the Stardust sample return capsule. Based on this result, a third grid ("C") was generated, which had 395 points in the axial direction and the same normal distribution as the previous grids. The solution on this grid was essentially the same as that obtained on grid $B$, indicating that grid $B$ has sufficient axial resolu tion. The final solution shown in Fig. 6 was obtained on a four block grid ("D") with 36,000 total grid points $(50 \%$ more than grid B). Axial spacing was essentially identical to grid $B$ ( 253 points on the surface); however the normal spacing was set to at constant value of $10^{-5}$ $m$ over the entire surface, and most of the additional points were clustered in the separated flow region using the compact enrichment technique described earlier. The computed heat transfer on this grid is essentially identical to that obtained on grid B, indicating that at these low Reynolds numbers the near wall spacing and normal resolution of the separated flow region are not critical to predicting heat transfer. No unsteadiness 


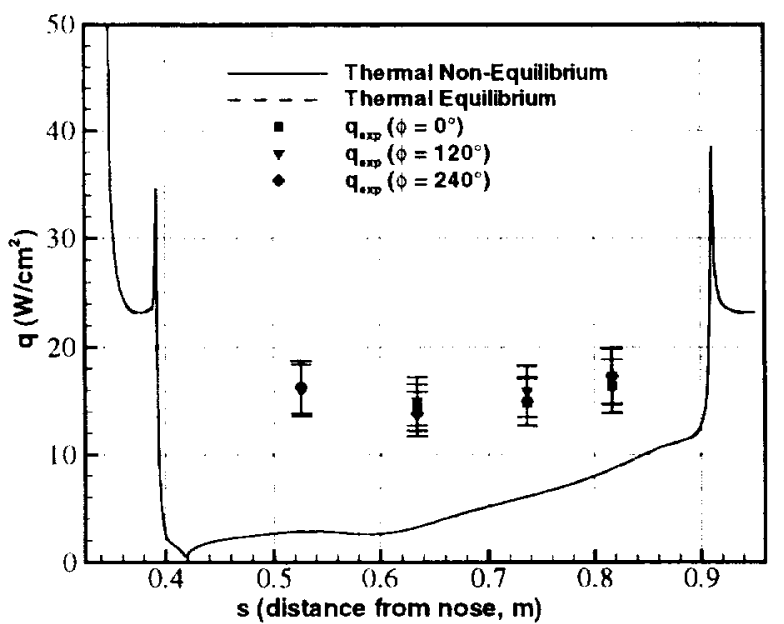

Figure 7. Effect of the thermal state of the gas on computed afterbody heat transfer at $t=1639 \mathrm{~s}$.

was observed in any of the solutions obtained for this study.

$\Lambda$ similar study wis performed at $t=1631 \mathrm{~s}$. At this point, the Reynolds number is a factor of five lower than at $t=1639 \mathrm{~s}$, and is expected there is less sensitivity to grid refinement. For this case the computed afterbody heat transfer varied less than $5 \%$ on all grids tested. These results indicate that grid resolution is not the cause of the disigreement between the flight datit and the computations.

\section{Sensitivity to the gas thermal state}

The effect of the assumed thermal state of the gas is shown in Fig. 7 for $t=16: 39 s$. The thermal nonequilibrium solution is obtained using the method described above, while the equilibrium solution is computed using statistical mechanics to model the vibrational energy of the gas at the single temperature $T$. As seen in Fig. 7 , the assumption of thermal equilibrium vs. nonequilibrium has no impact on the computed heat transfer. The same is true for all other trajectory points as well. 'This result is due to the fact that the post shock flow consists entirely of at omic species and their ions; there are essentially no molecules to carry the vibrational energy. Since the forebody wall boundary condition is non-catalytic to nentral species, there is little recombination occurring in the near-wall region on the forebody, and thus the wake core will consist mainly of atoms as well. For example, at $t=1639 \mathrm{~s}$ the maximum mass fraction of diatomic species in the wake is loss than 3\%. However, for a less energetic flow, of for a forebody surface that is catalytic to neutrals, one would expect the thermal state of the gas to have a larger influence on the wake core. ${ }^{34}$

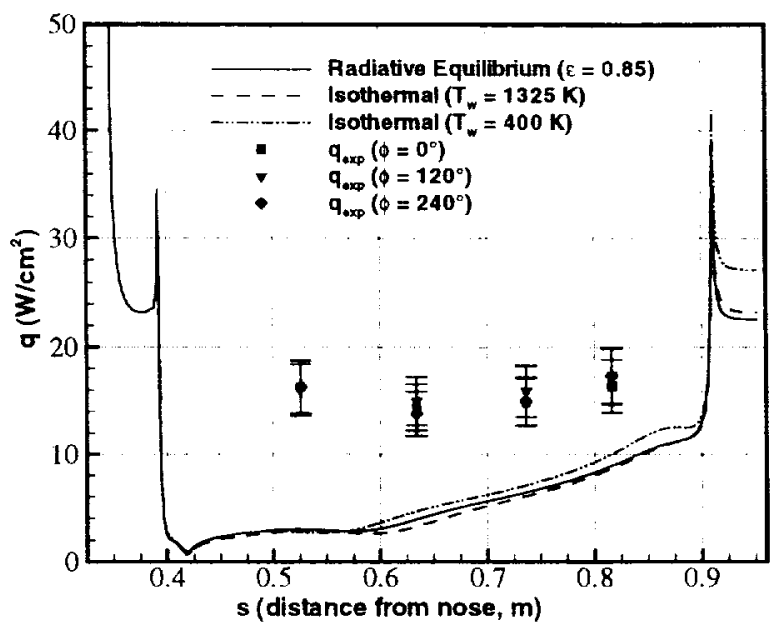

Figure 8. Effect of the thermal wall boundary condition on computed afterbody heat transfer at $t=1639 \mathrm{~s}$.

\section{Sensitivity to surface temperature}

In the preliminary computations an isothermal wall was assumed, with the wall temperature taken to be the same as that for the forebody. However, the materials used on the afterbody heat shield are much less conductive than the beryllium forebody. This would imply that perhaps a radiative equilibrium boundary condition would be more appropriate, in which conduction into the surface is assumed to be zero and the heat convected to the surface is balanced by that radiated away. Heat transfer to the surface then becomes a function of the surface temperature, given by $\dot{y}_{\text {tot }}=\epsilon \sigma T_{w}^{4}$, where $\epsilon$ is the surface emissivity, $\sigma$ is the Stefan-Boltzmann constant, and $T_{w}$ is the wall temperature. At the other extreme, we can use the thermocouple data directly to predict an afterbody temperature. The thermocouple data indicate a temperature of about $100 \mathrm{~K}$ at $t=1639 \mathrm{~s}$. This tempera. ture is slightly misleading, since the thermocouples are attached to highly conductive gold calorimeter slugs, rather than the much less conductive phenolic asbestos afterbody material. However, it provides another data point which can be used to assess the sensitivity of the heat transfer to the applied thermal boundary condition. Figure 8 shows the results of this analysis for $t=1639 \mathrm{~s}$. Results are shown for a radiative equilibrium wall $(\epsilon=0.85)$, a "hot" isothermal wall $\left(T_{w}=1325 \mathrm{~K}\right)$, and a cold wall $\left(T_{w}=400 \mathrm{~K}\right)$. In each case the forebody temperature was held constant. The wall temperature on the conical frustum for the radiative equilibrium solution ranged from about $700 \mathrm{~K}$ at the beginning $(s=0.42 \mathrm{~m})$ to about $1300 \mathrm{~K}$ at the end $(s=0.90 \mathrm{~m})$. From the figure we see that decreasing wall temperiture tend to increase surface 
a)
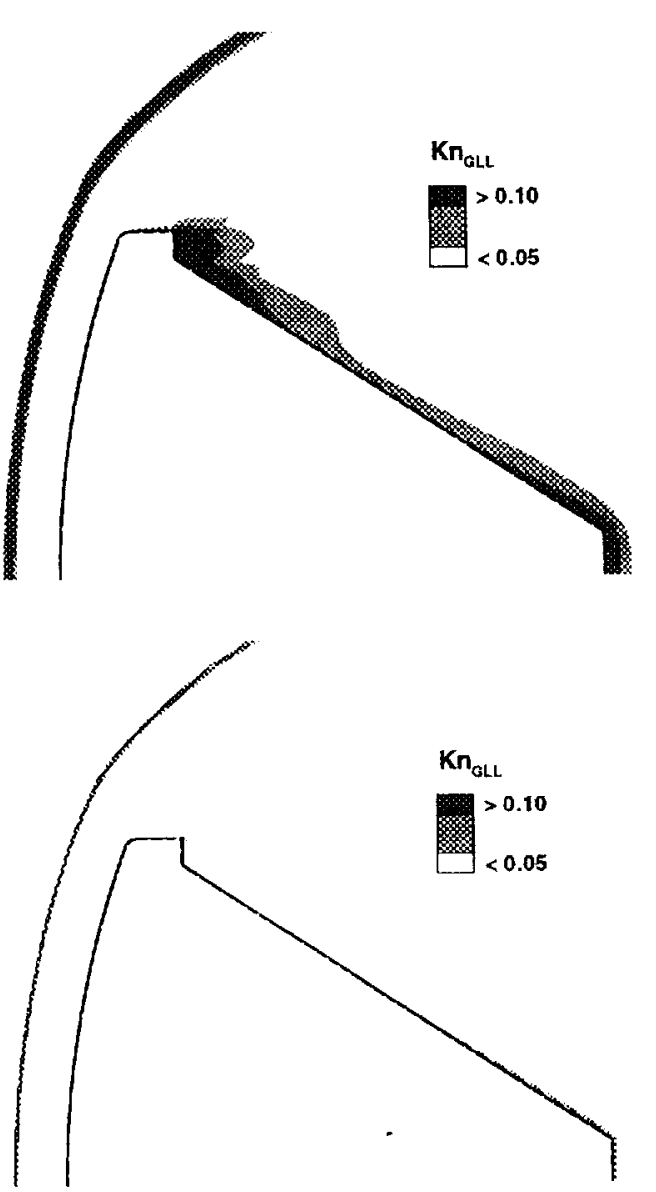

b)

Figure 9. Assessment of continuum flow assumption, an measured by the gradient length local Knudsen number $\left(K n_{a L L}\right)$. The continuum flow assumption is generally assumed to be fully valid in regions

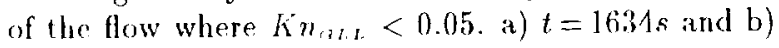
$t=1639$ s.

beat transfer, atthough the increase on the frustum is small $(<10 \%)$ as compared the the discrepancy be tween the flight data and the computation. Interestingly, the flat base $(s>0.9) \mathrm{m}$ ) was more sensitive to the wall temperature, with the heat transfer increasing by more than $20 \%$ in the wall temperature was lowered from its radiative equilibrium value $(1500 \mathrm{~K})$ to $100 \mathrm{~K}$. Ilowever, since this region of the vehicle was simplified during construction of the OML, this effect wats not explored further.

\section{Sencitivity to non-continum effects}

The solutions shown in this paper were obtained as suming a continuum flow. Ilowever, at these Reynolds mumbers non continumum effects may be present in the bitse region. In order to assess the importance of non cont inumu effects on computed heat transer, the gra- dient length local Knudsen number $\left(K n_{\text {GLL }}\right)^{35}$ was computed for the $t=1634$ and $t=1639$ second trajectory points, with the results shown in Fig. 9. Following the work of Boyd et. al. ${ }^{35}$ continuum breakdown can be expected to begin when $K n_{O L L}>0.05$. From Fig. 9a we see that at $t=1634 \mathrm{~s}\left(\operatorname{Re}_{D}=2 \times 10^{4}\right)$ there are significant non continuum effects in the near wall region of the afterbody. However, at $t=1639 \mathrm{~s}$ $\left(R e_{D}=1 \times 10^{5}\right)$ continuum breakdown is much less severe, and is confined to the last third of the conical frustum and the flat base (Fig. 9b). Unfortunately, Boyd et. al. did not quantify the relationship between $K n_{O L L}$ and computed heat transfer. However, a Navier-Stokes solution in general will slightly overpredict heat transfer in the base region of a non continuum flow. ${ }^{36}$ Slip wall boundary conditions would permit a more rigorous estimate of non-continuum effects with a Navier-Stokes code, and would capture this slight decrease in heat transfer. However, full implementation of a slip wall boundary condition in a reacting flow code is a non-trivial effort, ${ }^{37}$ which has not been completed in DPLR-Axi at this time.

\section{Sensitivity to surface catalysis}

The afterbody surface was initially assumed to be non-catalytic to neutral species. However, rince the wake core consists almost entirely of dissociated atoms, any surface catalycity would have a large impact on the heat transfer. Although the materials used in the construction of the Fire II afterbody heatshield are no longer in production, it is possible to draw some analogies to current materials. Based on analysis of silicon and carbon-phenolics, the surface coating and the underlying phenolic resin would likely start to pyrolyze when the surface temperature exceeded about $700 \mathrm{~K}$. Vigorous pyrolysis would occur by about $800 \mathrm{~K}$, and the process would be complete by the time the surface reached about $1100 \mathrm{~K}$. 38 The end product of this py. rolysis would be a surface layer of carbon char, which should be nearly fully catalytic. However, this char would be mixed with asbestos fibers, which are essentially a ceramic material with very low catalycity. As stated previously, the surface temperature of the heat shield is not known accurately, making it is difficult to predict the onset of pyrolysis. However, the effects of surface catalycity can be bounded by assuming a fully catalytic surface $\left(\gamma_{\text {neutrals }}=\gamma_{i o n}=1\right)$. In addition, a supposition ${ }^{30}$ is made that, prior to the onset of pyrolysis, the surface catalycity of the silicon based coating would be similar to that of SIRCA, ${ }^{40}$ for which atcommodation coefficients for nitrogen and oxygen recombination at a function of temperature are known. ${ }^{41}$ 


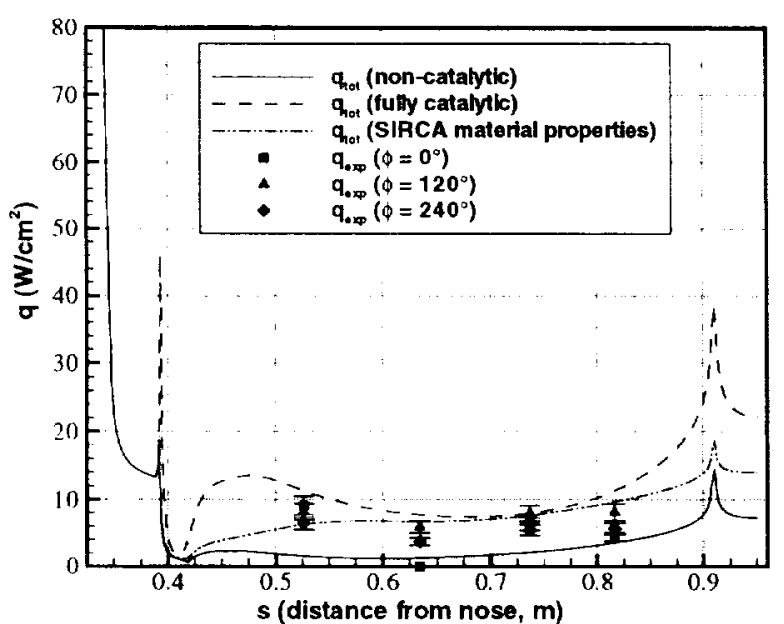

a)

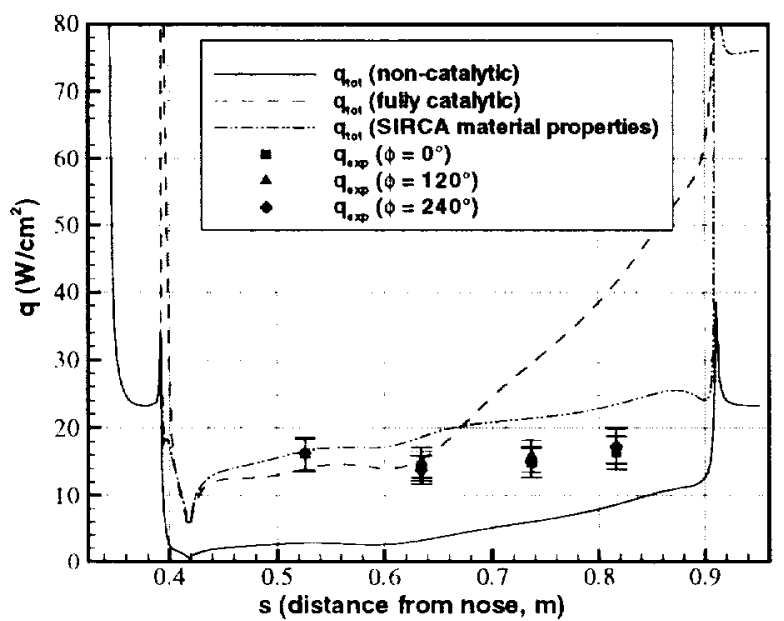

b)

Figure 10. Comparicon between heat transfer computed using several catalysis models on the afterbody with experimental data. it) $t=1634 \mathrm{~s}$ and b) $t=1639 \mathrm{~s}$.

Based on this analyis, solutions are obtained for each of the five trajectory points on the baseline grid, assuming an afterbody surface that is non-catalytic, fully atalytic, and partially catalytic using the rates for SIRCA. In all cases a radiative equilibrium wall is assumed. Results for $t=1634 \mathrm{~s}$ are shown, together with the experimental data, in Fig. 10a. The assumption of catalysis on the afterbody significantly increases predicted heat transfer. As expected, ${ }^{42}$ both catalytic solutions show a pronounced catalytic "spike" at the rear of the shoulder $(s=0.38 \mathrm{~m})$, where the highly dissociated gas flows over the surface tranition from a non-catalytic to a catalytic surface. In addition, both solutions predict much higher heating on the flat base. This rosult is due to the fact that the flow is reparated, and thus the highly dissociated wake flow first comes in contact with the catalytic surface in the base. As the reverse flow travels forward on the frustum the flow rapidly recombines, depositing its energy preferentially on the trailing end of the frustum. This effect is less pronounced for the SIRCA case, both because less catalysis is occurring and because the SIRCA rates are temperature dependent. The hump in heat transfer for the fully catalytic solution around $s=0.15 \mathrm{~m}$ is due to the fact the flow does not separate at the corner at this low Reynolds number (see Fig. 1), and thus there is a region of dissociated forward flow on the first part of the frustum. Once again, there is little scatter in the experimental data, with the exception of a spurious zero reading at $s=0.63 \mathrm{~m}, \phi=0^{\circ}$. The non-catalytic solution significantly underpredicts the data, which is consistent with the results shown previously for $t=1639 \mathrm{~s}$. However, the fully catalytic solution slightly overpredicts the data, while the partially catalytic SIRCA solution is generally in good agreement.

Figure 10b shows the same results for $t=1639 \mathrm{~s}$. For this case the catalytic jumps at the rear of the shoulder and on the flat base are much larger, as expected. The SIRCA computation shows the best agreement with the data, although the heat transfer is overpredicted at the final two s-locations. The fully catalytic afterbody solution drastically overpredicts heating at these locations. Interestingly, the fully catalytic solution predicts lower heat transfer on the forward part of the frustum for this case than the SIRCA solution. This effect appears to be due to the fact that for the fully catalytic case, much of the recombination (and associated heat release) is occurring at the back end of the frusturn, while for SIRCA the slower recombi nation rates result in catalytic heat release along the entire surface.

The trends in the dat a become more clear if we plot heat transfer vs. time at each calorimeter location, as shown in Fig. 11 for each of the four $x / L$ calorimeter locations, where $x / L=0$ at the rearward facing step on the heatshield shoulder and $x / L=1$ at the theo. retical apex of the conic frustum. In these plots, the solid lines are the experimental data from the three circumferentially distributed calorimeters at each $x / L$ location, the dashed lines represent the assumed $\pm 15 \%$ uncertainty in the experimental data, and the symbols are the results of the CFD computations for a non catalytic, fully catalytic, and SIRCA surface. From the figure, we see that the non-catalytic predictions are low throughout the trajectory. The fully catalytio and SIRCA predictions show good agreement with the data at $x / L=0.19$ and $x / L=0.38$ over the entire tra 


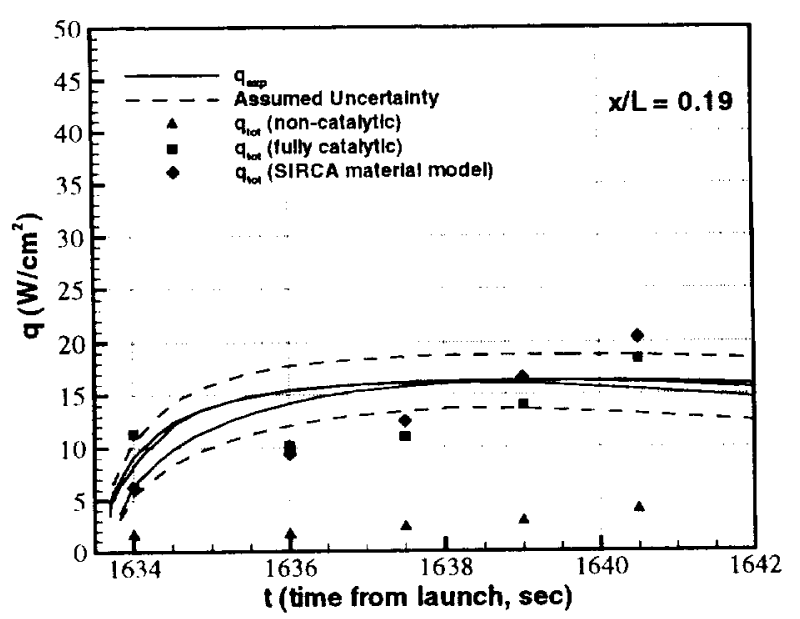

a)

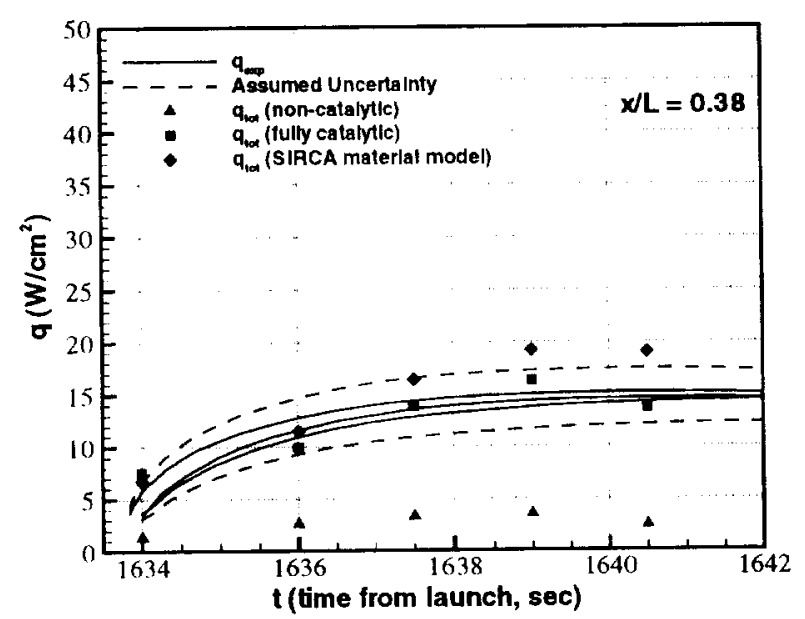

b)

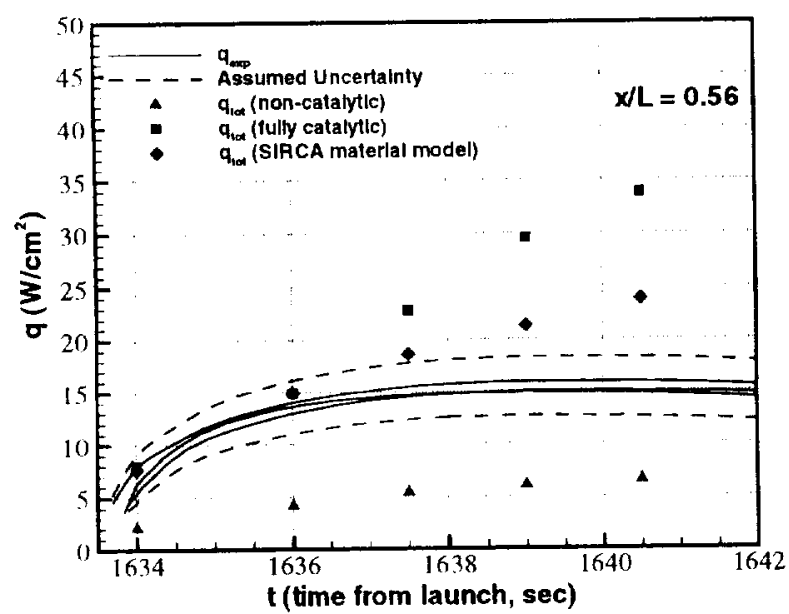

c)

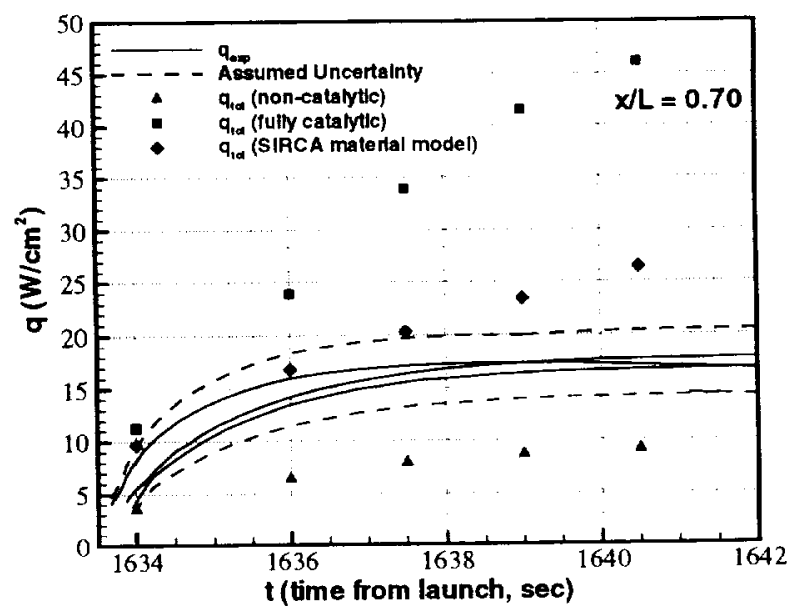

d)

Figure 11. Time histories of total heat transfer computed using several catalysis models on the after body as compared to flight data. a) $x / L=0.19$, b) $x / L=0.38$, c) $x / L=0.56$, and d) $x / L=0.70 . x$ and $L$ are defined in Fig. 1.

jectory range examined here. However, at $x / L=0.58$ and $x / L=0.70$ a different trend is seen. While the SIRCA prediction is in good agreement with the data up to $t=1637.5 \mathrm{~s}$, the fully catalytic solution has begun to significantly overpredict heating by this time. In addition, as $t$ increases, the heat transfer predicted by both catalytic solutions continues to rise, while the flight data appear to level off at $15-17 \mathrm{~W} / \mathrm{cm}^{2}$. From a design standpoint, some comfort can be taken from the fact that the fully catalytic prediction is conservative over the later (highest heating) portion of the trajectory. However, the amount of conservatism in this solution on the last half of the frustum would lead to unnecessarily large margins on the heat shield thickness if it were used as a basis for design.

Figure 12 shows the experimental heating data for $x / L=0.56$ over the entire trajectory. Profiles at the other locations have a similar shape. Also shown in Fig. 12 is the total (convective and radiative) heat transfer measured at the forebody stagnation point. Gaps in the forebody heating data correspond to periods of calorimeter melting and ejection. From Fig. 12 it is clear that the afterbody heating on the frustum reached a maximum about six seconds earlier than the forebody stagnation point. This result is contrary to computations used for Stardust heatshield design, ${ }^{34}$ and flight data from a thermocouple located on the conical frustum of the Mars Pathfinder entry vehicle, ${ }^{43}$ which both showed that maximum heating on the afterbody frustum occurred concurrent with or after forebody peak heating. This discrepancy implies 


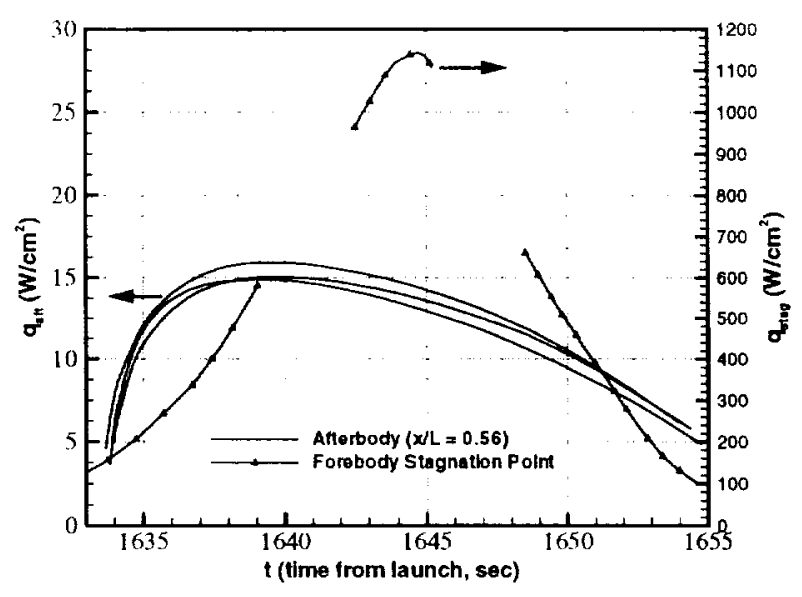

Figure 12. Time histories of total heat transfer measured during flight on the conical frustum at $x / L=$ 0.56 , and at the forebody stagnation point. Gaps in the forebody heat transfer curve correspond to periods of heatshield melting and ejection.

that there was some physical process occurring during during the Fire II entry that was not observed in the Stardust computations or the Pathfinder entry. It is difficult to identify the mechanism that caused the experimental heat transfer to level off at around $t=1638 \mathrm{~s}$ without a more detailed investigation of the material response of the surface. However, one possibility is that pyrolysis is beginning at around this time. The onset of pyrolytic blowing would reduce the heat transfer to the surface over that predicted here. Pyrolysis did not occur on the Pathfinder afterbody, since peak heat transfer rates were an order of magnitude smaller than those encountered by Fire II. Another possibility is the assumption of at non-catalytic forebody. If the forebody were partially atalytic to neutrals, the roncentration of atoms in the wake core would be reduced, lowering the magnit ude of the catialytic jump at the trailing end of the frustum and on the base plate.

\section{Future Work}

This paper makes it start at analyzing the afterbody data from the Fire II flight experiment with CFD. While good agrement was obtained over a portion of the trajectory assuming a catalytic afterbody, a great deal more work needs to be done. The properties of the afterbody materials should be studied in detail, in order to improve the catalysis and thermal boundary conditions. Material response should be coupled to the (FI) colutions to model the onset of pyrolysis. 'Threedimensional simulations with conpled conduction would allow us to model the different materials that make up the calorimeter surface (oxi- dized nickel-chrome) and the phenolic-asbestos afterbody heat shield. Although the rearward facing radiometer did not show any incident radiation, there was a significant amount of radiative heating to the forebody. This radiation was shown to be weakly coupled to the flow, slightly altering the nat ure of the forebody flowfield. ${ }^{4}$ This coupling could affect the shoulder expansion process and thus the wake core. The rates used here for chemical and energy exchange processes were mainly derived from experimental data in compressive flows, and thus the universal applicability of these models in a base flow simulation, which combines a compressive and strongly expanding flow region, is uncertain. ${ }^{29}$ Finally, if data from later in the trajectory are to be examined, turbulence becomes an issue and appropriate turbulence models must be applied.

\section{Conclusions}

The wake flow and afterbody heating environment of the Project Fire II flight experiment were simulated using computational fluid dynamics. Results were ob tained over the first portion of the trajectory, spanning the period from the onset of significant afterbody heating to the peak heating point. Computed heat transfer on the conical frustum portion of the afterbody was compared to the flight data. Although forebody heating results showed excellent agreement with previous computations, the initial non-catalytic predictions of afterbody heating were about a factor of two below the experimental values. Grid resolution of the solutions was confirmed and some of the modeling assumptions used during the CFD simulations were examined as possible sources of error. This analysis pointed to the possibility that catalysis was occurring on the afterbody heat shield. Computations were then made as suming both a fully catalytic afterbody surface, and a partially catalytic surface using a material model for SIRCA, which was chosen to approximate the catalytic properties of the surface coating prior to the onset of pyrolysis. The computations including finiterate catalysis, particularly the SIRCA model, are in good in good agreement with the data over the early portion of the trajectory. However, the catalytic results are conservative near the peak afterbody heating point, especially on the rear portion of the conical frustum. Comparison of the computations and flight data from Fire II with previous data suggests that another mechanism, possibly pyrolysis, may be occurring during this portion of the flight, reducing the total heat transfer over the predictions that do not include material response. Although more work needs to be done, these results give increased confidence in the ability of CFD to, both conservatively and accurately, pre: 
dict the afterbody heating environment of a planetary entry vehicle during the liminar portion of the trajectory.

\section{Acknowledgments}

The authors would like to thank Carol Davies (ELORET, NASA ARC) for her help using SAGE, Dr. Peter Gage (ELORET) for assistance in creating the OML, and Drs. Ethiraj Venkatapathy, Dinesh Prabhu, Deepali Bose (All ELORET), Mr. Howard Golktein (RIACS), and Mr. Bernard Laub (ARC) for their valuable technical insights. The work performed by the 1st and $3 \mathrm{rd}$ aluthors was supported by the prime contract NAS2-99092 to ELORET.

\section{References}

1 Cornette, E.S., "Forobody Temperatures and Calorime ter Heating Rates Measured During Project Fire II Reentry at $11.35 \mathrm{~km} / \mathrm{s}, "$ NASA TM X 1305, 1966.

' Cauchon, D.L., "Radiative Heating Results from the Fire II Flight Experiment at Reentry Velocity of $11.1 \mathrm{~km} / \mathrm{s}$," NASA TM X-1102, 1967.

"Slocumb, T.H., "Projoct Fire II Afterbody Temper itures and Pressures at 11.35 Kilometer Per Sec ond," NASA TM X 1:319, 1966.

4 Olynick, D.R., W.I). Henline, L. Hartung-Chambers, and (i.V. Candler "Comparisons of Compled Radiative Navier-Stokes llow Solutions with the Project Fire Il Flight Data." AIAA Paper No. 91-1955, June 1994

"Greendyke, R.B. and L.C. Hartung, "Convective and Radiative Heat Transfer Analysis for the Fire II Forebody," Ioumal of Spacecraft and Rockcts, Vol. 31, No. 6, Nov. 1991, pp. 986992.

F Gokcen, T., "Computation of Nonequilibrium Radiating Shock Layers," Journal of Thermophysics and Hoat Transfer, Vol. 9. No. 1, Jan. 1995, pp. 31-10.

† Balakrishnan, A., ( . l'ark, and M.J. Green, "Radia live Viscous Shock Layer Analysis of Fire, Apollo, ind PAET Flight Dat i," AIAA Paper No. 85-1061, June 1985.

" cilpta, R.N., "Nivier Stokes and Viscous ShockLatyer Solutions for Radiating Hypersonic: Flows," AlAA Piper No. 87 1576, June 1987.

"Zappa, O.L. and W.(: Reinecke, "An Experimentat Investigation of Batse Heating on Typical Mars Entry Body Shapes," NASA CR 1920, Nov. 1971.

10 Slocumb, T.H., "project Fire I Heating and Pres - lure Meatsurements on the Reentry Vehicle Afterbody it a Volocity of 38,000 Fent Per Second," NASAA TM X 1178, 1965.

11 Lewis, J.II. and W.I. Scallion, "Flight Parameters and Vehicle Perfommance for Project Fire Flight II Latunched May 22, 1965," NASA TN I) 3569,1966
12 Lee, J.H., "Basic Governing Equations for the Flight Regimes of Aeroassisted Orbital Transfer Vehicles," Thermal Design of Aeroassisted Orbital Transfer Vehicles, H.F. Nelson ed., Progress in Astronautics and Aeronautics, Vol. 96, AIAA, 1985, pp. $3-53$.

13 Candler, G.V., "The Computation of Weakly Ionized Flows in Chemical Nonequilibrium," PhD. Thesis, Stanford University, 1988.

14 Gnoffo, P.A., R.N. Gupta, and J.L. Shinn, "Conservation Equations and Physical Models for $\mathrm{Hy}$ personic Air Flows in Thermal and Chemical Nonequilibrium," NASA TP 2867, Feb. 1989.

15 Park, C., "Review of Chemical-Kinetic Problems of Future NASA Missions, I: Earth Entries," Journal of Thermophysics and Heat Transfer, Vol. 7, No. 3. 1993, pp. 385-398.

16 Wilson, J., "Ionization Rates of Air Behind High Speed Shock Waves," Physics of Fluids, Vol. 9, No. 10, 1966, pp. 1913-1921.

17 Millikan, R.C. and D.R. White, "Systematics of Vibrational Relaxation," Journal of Chemical Physics, Vol. 39, No. 12, 1963, pp. 3209-3213.

18 Gupta, R.N., J.M. Yos, R.A. Thompson, and $K$. Lee, "A Review of Reaction Rates and Thermodynamic and Transport Properties for an 11-Species Air Model for Chemical and Thermal Nonequilibrium Calculations to $30,000 \mathrm{~K}$," NASA RP 1232, 1990 .

10 Bartlett, E.P., R.M. Kendall, and R.A. Rindal, "An Analysis of the Coupled Chemically Reacting Boundary Layer and Charring Ablator: Part IV A Unified Approximation for Mixture Transport Properties for Multicomponent BoundaryLayer Applications," NASA CR 1063, June 1968.

20 Lees, L., "Hypersonic Wakes and Trails," $A I A A$ Journal, Vol. 2, No. 3, Mar. 1961, pp. 117-128.

21 Park, C., "Nonequilibrium Hypersonic Aerothermodynamics," John Wiley and Sons, New York, 1990.

22 Pope, R.B., "Stagnation Point Convertive Heat Transfer in Frozen Boundary Layers," AIAA Journal, Vol. 6, No. 1, Apr. 1968, pp. 619-626.

23 Winkler, E.L. and R.E. Sheldahl, "Influence of Calorimeter Surface Treatment on Heat Transfer Measurements in Arc-Heated Test Streams," AIAA Journal, Vol. 1, No. 1, A pr. 1966, pp. 715-716.

24 Wright, M.J., G.V. Candler, and D. Bose, "A Data Parallel Line Relaxation Method for the Navier Stokes Equations," AIAA Journal, Vol. 36, No. 9, 1998 , pp. $1603-1609$.

25 MacCormack, R.W. and G.V. Candler, "The Solution of the Navier-Stokes Equations Using GallssSeidel Line Relaxation," Computers and Flunds, Vol. 17. No. 1, 1989, pp. 135-150.

26 Yee, H.C., "A Class of Iligh-Resolution Explicit 
and Implicit Shock Capturing Methods," NASA TM 101088, 1989.

27 Olejniczak, J. and D.G. Fletcher, "An Experimental and Computational Study of the Freestream Conditions in an Arc-Jet Facility," AIAA Paper No. 20002567 , June 2000.

28 Wright, M.J., K. Sinha, J. Olejniczak, G.V. Can dler, T. D. Magruder, and A. J. Smits, "Numerial and Experimental Investigation of Double-Cone Shock Interactions," AIAA Journal, Vol. 38, No. 12, 2000 , pp. 2268-2276.

20 Gnoffo, P.A., J.M. Price, and R.D. Braun, "Computation of Near Wake Aerobrake Flowfields," Journal of Spacecraft and Rockets, Vol. 29, No. 2, March 1992, pp. 182-189.

30 Haas, B.L. and E. Venkatapathy, "Mars Pathfinder Computations Including Base-Heating Predictions," AlAA Paper No. 95-2086, June 1995.

3 Pointwise Inc, Gridgen Users Manual Version 12, Bedford 'TX, 1997.

32 Davies, C.B. and E. Venkatapathy, "The SelfAdaptive Grid code SAGE, Version 3," NASA TM 208792, Aug. 1999

34 Program Development Corp., GridPro/az3000 Users Guide and Reference Manual, White Plains NY, 1996.

34 Olynick, D.R., Y.K. Chen, and M.E. Tauber, "Aerothermodynamics of the Stardust Sample Return Capsule," Journal of Spacecraft and Rockets, Vol. 36, No. 3, May 1999, pp. 142-162.

35 Boyd, I.D., G. Chen, and G.V. Candler, "Predicting Failure of the Continuum Fluid Equations in Transitional Hypersonic Flows," Physics of Fluids, Vol. 7. No. 1, pp. $210.219,1995$.

36 Dogra, V.K., J.N. Moss, R.G. Wilmoth, J.C. Taylor, and H.A. Hassin, "Effects of Chemistry on Blunt Body Wake Structure," AIAA Paper No, 910352, Jan. 1994.

37 Gupta, R.N., C.D. Scott, and J.N. Moss, "Slip Boundary Conditions for Multicomponent Nonequilibrium Airflow," NASA TP 2152, Nov. 1985.

3* Laub, B., NASA Ames Thermal Protertion Branch, Private Communication, 2001.

39 Croldstein, H., NASA Ames Space Technology Division, Private Communication, 2001.

4! Tran, H., C. Johnson, D. Rasky, and F. Hui, "Silicon Impregnated Rensible Ceramic: Ablators for Mars Follow-on Missions," AIAA Paper No. 961819, June 1996 .

11 Stewart, D.A., "Surface Catalysis and Characterization of Proposed cindidate TPS for Access-to Space Vehicles," NASA TM 112206. .July 1997.

42 Prablu, I).K., E. Voukatapathy, D.A. Kontinos, and P. Papadoponlon, "X 33 Catalytic Heating,"
AIAA Paper No. 98-2811, June 1998.

${ }^{43}$ Milos, F.S., Y.K. Chen, W.M. Congdon, and J.M. Thornton, "Mars Pathfinder Entry Temperature Data, Aerothermal Heating, and Heatshield Material Response," Journal of Spacecraft and Rockets, Vol. 36, No. 3, May 1999, pp. 380-391. 